\title{
What is the real number of Lyme disease cases in Canada?
}

\author{
N. H. Ogden ${ }^{1 *}$ (D, C. Bouchard ${ }^{1}$, J. Badcock ${ }^{2}$, M. A. Drebot ${ }^{3}$, S. P. Elias ${ }^{4}$, T. F. Hatchette ${ }^{5}$, J. K. Koffi ${ }^{6}$, P. A. Leighton ${ }^{7}$, \\ L. R. Lindsay ${ }^{3}$, C. B. Lubelczyk ${ }^{4}$, A. S. Peregrine ${ }^{8}$, R. P. Smith ${ }^{4}$ and D. Webster ${ }^{9}$
}

\begin{abstract}
Background: Lyme disease is emerging in Canada due to expansion of the range of the tick vector /xodes scapularis from the United States. National surveillance for human Lyme disease cases began in Canada in 2009. Reported numbers of cases increased from 144 cases in 2009 to 2025 in 2017. It has been claimed that few (< 10\%) Lyme disease cases are reported associated with i) supposed under-diagnosis resulting from perceived inadequacies of serological testing for Lyme disease, ii) expectation that incidence in Canadian provinces and neighbouring US states should be similar, and iii) analysis of serological responses of dogs to the agent of Lyme disease, Borrelia burgdorferi.

We argue that performance of serological testing for Lyme disease is well studied, and variations in test performance at different disease stages are accounted for in clinical diagnosis of Lyme disease, and in surveillance case definitions. Extensive surveillance for tick vectors has taken place in Canada providing a clear picture of the emergence of risk in the Canadian environment. This surveillance shows that the geographic scope of I. scapularis populations and Lyme disease risk is limited but increasing in Canada. The reported incidence of Lyme disease in Canada is consistent with this pattern of environmental risk, and the differences in Lyme disease incidence between US states and neighbouring Canadian provinces are consistent with geographic differences in environmental risk. Data on serological responses in dogs from Canada and the US are consistent with known differences in environmental risk, and in numbers of reported Lyme disease cases, between the US and Canada.

Conclusion: The high level of consistency in data from human case and tick surveillance, and data on serological responses in dogs, suggests that a high degree of under-reporting in Canada is unlikely. We speculate that approximately one third of cases are reported in regions of emergence of Lyme disease, although prospective studies are needed to fully quantify under-reporting. In the meantime, surveillance continues to identify and track the ongoing emergence of Lyme disease, and the risk to the public, in Canada.
\end{abstract}

Keywords: Lyme disease, Borrelia burgdorferi, Surveillance, Under-reporting, Canada

\section{Background}

Lyme disease (LD), caused by the bacterium Borrelia burgdorferi sensu stricto (for simplicity referred to hereafter as Borrelia burgdorferi), is an emerging infectious disease in eastern and central Canada due to the northward spread of the tick vector Ixodes scapularis [1] (also known as the blacklegged tick). Lyme disease is a zoonosis, and the ecology of this disease has been extensively reviewed (summarized in [2]). The natural reservoirs of B. burgdorferi are small and medium sized wild mammals (particularly mice

\footnotetext{
*Correspondence: nicholas.ogden@canada.ca

'Public Health Risk Sciences Division, National Microbiology Laboratory,

Public Health Agency of Canada, St. Hyacinthe, Canada

Full list of author information is available at the end of the article
}

of the genus Peromyscus) and birds. Immature Ixodes species ticks feed on these hosts and maintain B. burgdorferi transmission cycles. Deer are not reservoirs for $B$. burgdorferi but are the hosts for adult female ticks, so LD risk is indirectly related to deer densities. The vector ticks require woodland habitat because woodlands provide suitable densities of their wild animal hosts, and because they provide duff layer refuges that permit ticks to survive extremes of temperature in winter and summer during periods that they are not feeding on hosts. LD emerged in northeastern and upper Midwestern US in the 1970s, likely associated with changes in land use that resulted in increased woodlands allowing deer and then tick and B. burgdorferi populations to expand out of refugia [2]. Range expansion is

(c) The Author(s). 2019 Open Access This article is distributed under the terms of the Creative Commons Attribution 4.0 International License (http://creativecommons.org/licenses/by/4.0/), which permits unrestricted use, distribution, and reproduction in any medium, provided you give appropriate credit to the original author(s) and the source, provide a link to the Creative Commons license, and indicate if changes were made. The Creative Commons Public Domain Dedication waiver (http://creativecommons.org/publicdomain/zero/1.0/) applies to the data made available in this article, unless otherwise stated. 
facilitated by dispersal of ticks and bacterium over short distances by terrestrial hosts, and long distances by migratory birds [3]. The latter may have been particularly important in seeding I. scapularis and B. burgdorferi populations in Canada, as migratory birds leap-frog geographic barriers to terrestrial host movements such as the Great Lakes, the Appalachian Mountains and the sea [4-7]. Northward range expansion of $I$. scapularis into Canada, and subsequent emergence of LD, have been associated with effects of climate change on the biology of the tick; multiple studies have identified associations between temperature and the spatio-temporal pattern of spread of the ticks [8]. However, effects of climate warming on hosts of $I$. scapularis and B. burgdorferi may also be contributing to LD emergence [9]. In British Columbia, the vector of B. burgdorferi is Ixodes pacificus (the western blacklegged tick), which has been widespread in the south of the province for many years [10]. The risk of acquiring LD from bites of this tick species is considerably lower than from I. scapularis in the east, as few I. pacificus ticks are infected and they are less likely to bite humans than I. scapularis [11]. Since LD became nationally notifiable in Canada in 2009, the number of reported cases has increased more than tenfold from 144 cases to 2025 cases reported in 2017 [12]. This increase in incidence is consistent with the range spread of I. scapularis ticks in Canada [13], but other factors may modulate the risk of LD to the Canadian public via effects on rates of their exposure to tick bites. These include forest fragmentation, construction of residences in newly-established LD risk areas, and changes in knowledge and perception of LD risk and prevention methods $[9,14,15]$. It is unlikely that all LD cases are reported, however the precise rate of under reporting of $\mathrm{LD}$ in Canada is not known.

Infectious disease surveillance systems aim to elucidate patterns of a disease within a population and, by understanding these, inform public health policies and programs to reduce risk from that disease [16]. Surveillance systems often underestimate the "true" frequency of a disease in a population due to i) under-ascertainment (i.e. not all cases seek health care), and ii) underreporting (i.e. not all symptomatic cases that have sought health care are captured by the surveillance system) [17]. Some definitions of under-ascertainment include cases that are not correctly diagnosed [17]. In some surveillance systems, the rate of under-reporting can be high (e.g. less than one 100th of infectious gastrointestinal illnesses were reported in Ontario in the 1990s [18]). However, if under-reporting is equal in the groups assessed by the surveillance system, trends should still be detectable and can be extrapolated to the population as a whole. If under-reporting is not equal, valid analyses are still possible if the inequalities are known and can be adjusted for, allowing estimation of the burden of illness $[18,19]$.
The under-reporting of LD cases through passive surveillance in the United States has been evaluated in a number of studies with estimated ranges of reporting of $10-90 \%$. In regions with emerging infections, only one third of cases are likely identified in surveillance, due to issues common to emerging diseases, including limited knowledge of physicians about the disease, case definitions and the need to report [20]. In US states with high incidence, up to $90 \%$ of LD cases may go unreported secondary to "reporting fatigue" by clinicians [21]. However, even with high levels of under-reporting, trends in incidence are captured [21]. Recently it has been suggested there is a very high degree of under-reporting of LD cases in human case surveillance in Canada (less than 1 in 10 cases reported) based on the poor sensitivity of diagnostic tests to detect cases in Canada, and lack of reporting of cases detected [22]. In this article we evaluate the extensive surveillance data available for Canada to explore the extent to which underreporting may be occurring here. In so doing we aim to highlight that public health in Canada is active and informed in understanding the risk of LD to the public.

\section{Main text}

\section{Serological diagnosis failure as a potential source of under-detection and under-reporting}

Some patient advocacy groups suggest that the "twotier" serological algorithm used for LD diagnosis; screening enzyme immunoassays (EIA) followed by confirmatory immunoblot testing (and test interpretation criteria) recommended by US Centers for Disease Control and Prevention (CDC) and supported by the Association of Medical Microbiology and Infectious Diseases (AMMI) Canada and the Public Health Agency of Canada (PHAC), is too insensitive and misses many cases [22]. This assertion is based on 1) the use of test performance data that do not consider the stage of infection [23], and 2) comparisons of test results that use CDC-recommended methods and test interpretations, with those conducted using alternative methods in private laboratories in the US [24].

Numerous studies have shown that the performance of serological tests depends on the stage of infection. A recent systematic review shows that the two-tier algorithm is insensitive in early localized LD but performs well in late LD, at which point sensitivity approaches 100\% [25]. If sensitivity is averaged across all stages of LD, the sensitivity of the diagnostic approach appears worse than it actually is [23]. Issues of sensitivity in early LD are well known, and are taken into consideration in recommendations to clinicians about i) when to request serological testing, ii) how to interpret test results, iii) the occasional need for repeat testing, and iv) the empiric treatment of patients in the face of negative test results. The 
latter is the correct course of action in patients with early localized infection with erythema migrans rash (EM) $[26,27]$. In North America, there is considerable strain diversity of $B$. burgdorferi sensu stricto and it is possible that variation amongst infecting strains results in variations in the capacity of infections to be detected by some sero-diagnosis kits [28]. However, if so, this variation would likely impact serodiagnosis in Canada and neighbouring states equally. Studies in Canada identified strains that had not, at the time of the studies, been detected in the US [29]. However, this was because of lack of effort to explore strains in states bordering Canada, which is a gap that was recently addressed [30].

False positive EIA and immunoblot results are known to occur because of cross reactivity with other bacterial and viral infections [31-33] and a positive test result has poor predictive value when patients do not have symptoms consistent with LD, and/or when they have a low likelihood of exposure to infected ticks [34, 35]. Hatchette et al. [36] assessed the level of background sero-positivity (using the two-tier algorithm) in the Nova Scotia population using 1855 residual sera from healthy persons undergoing blood tests as part of a regular health check-up. Of these samples, 215 were positive by a screening whole cell EIA test, none of which were positive on the confirmatory immunoblots. The sensitivity of the whole cell EIA test approaches $100 \%$ in late LD [25], so it is likely that no or very few samples negative by the whole cell EIA test would have tested positive in the two-tier algorithm. Therefore, this study indicates that there is a very low level of background seropositivity using the two-tier approach in the Nova Scotia population $(<0.2 \%)$. However, there was a high level of background positivity in the screening EIA, which is consistent with other studies [37, 38].

These data highlight two key points regarding serological diagnosis of Lyme disease. First, false-positivity rates of the two-tier algorithm, when using CDC-recommended test interpretation criteria, are low. In contrast, false-positivity rates (including false positive results in healthy controls) reach $>50 \%$ in some of the private US "specialist" laboratories that use alternative test interpretation criteria [24], making positive test results from these laboratories (using their own interpretation criteria) of limited diagnostic value. Second, false positive test results with the screening assays do not equate to "missed" LD cases, and they do not indicate under-detection of LD cases by serological diagnosis in Canada, as has been suggested [22]. They are simply falsepositive, which is precisely why a two-tier diagnostic approach is used to maximise specificity.

What does Canadian national and provincial human case surveillance suggest about under-reporting?

Although LD had been a reportable disease in many provinces since the late 1980s, national human case surveillance for this infection in Canada began in 2009 $[39,40]$. It comprises the National Notifiable Disease Surveillance System (NNDSS), and the Lyme Disease Enhanced Surveillance (LDES) system. The LDES was initiated by the Public Health Agency of Canada (PHAC) in 2010 in collaboration with some provinces to obtain more detailed data on LD cases.

Reporting of cases in national surveillance is distinct from clinical diagnosis. Cases reported in surveillance must meet criteria of clinical manifestations, laboratory test results (when appropriate), and (for confirmed cases) a history of possible exposure to infective tick bites. These criteria are necessarily more restrictive than those used for clinical diagnosis, and have been designed to minimise the numbers of cases reported that are not LD, and ensure valid and reliable trends in LD incidence that require public health action [39]. The high likelihood of negative serological test results in early localized infection does not mean that patients are not diagnosed and treated by their clinicians, or that these cases are not reported. Cases presenting with an EM rash and without laboratory evidence of infection can be reported as this is one of the alternative national surveillance case definition criteria $[39,40]$. The rates at which underand over-diagnosis of LD may be occurring due to limitations of front-line physician awareness of clinical and laboratory diagnosis recommendations $[41,42]$ is another matter, and will be best estimated by welldesigned prospective studies.

Amongst the objectives of the LDES system is the collection of data on the clinical manifestations of reported cases. These data are used to identify the proportion of cases that are early LD (i.e. EM rash), early disseminated LD (multiple EM, neuroborreliosis, or Lyme carditis), or late disseminated LD (Lyme arthritis) $[13,40]$. Analysis of these surveillance data shows that a low proportion are reported in the early LD stage (approximately $14 \%$ of cases acquired in known LD risk areas). However, in the US $70 \%$ of cases are reported at this stage [40]. A similar analysis of surveillance data from Ontario produced the same result [43] and together these suggest that in Canada either EM cases are being detected and diagnosed but not reported, or that LD is frequently only diagnosed in the disseminated LD stages. In data from the LDES system, previous manifestations of EM were recorded for many cases of disseminated LD and overall the proportion of cases with a history of EM was the expected 70\% [40], suggesting that much of the shortfall is due to LD not being diagnosed at the EM stage. This is consistent with studies on physician awareness [41], and with the observation that over time, the proportion of reported cases that are early LD has increased as efforts to improve physician and public awareness have been intensified. It also provides 
evidence of the utility of the surveillance system in identifying policies needed (in this case physician awareness [44]) to better protect Canadians from emerging LD.

\section{Why is reported incidence in Canada much lower than in neighbouring US states?}

LD emerged in the southern parts of New England states in the 1970s [45]. Re-forestation of farmland in the twentieth century allowed the expansion of the geographic range and abundance of $I$. scapularis and $B$. burgdorferi populations out of refugia in the northeast and upper Midwest of the US resulting in increased transmission of the infection to humans [2]. This range expansion has now reached southern Canada, facilitated by dispersion of $I$. scapularis and B. burgdorferi by migratory birds from the US [6], and a warming climate to increase environmental suitability for I. scapularis at the northern edge of the tick's range [8]. This has resulted in the emergence of LD on the Canadian side of the border. However, it is very clear that the risk of acquiring LD from the environment (i.e. the risk of acquiring bites of infected ticks) is different in Canada than in neighbouring US states. This difference is due to: i) different stages of emergence and the extent of geographic spread of I. scapularis and B. burgdorferi (both currently limited in distribution and less abundant/prevalent in Canada compared to southern parts of neighbouring US states), and ii) high levels of exposure of the US population in the southern parts of these states where both population densities and LD risk are higher. In addition, some differences in case definitions and reporting must be considered when comparing LD incidence in the two surveillance systems.

We have a good understanding of the level of environmental risk for LD due to extensive passive and active field surveillance for ticks in the US and Canada. A country-wide assessment of LD risk in the US environment was conducted in 2004 [46] with visits to 95 sites in 37 states east of the 100th meridian, and this revealed the greatest risk in states of the upper Midwest and northeast. Many of these states border Canada and many, including Maine, Minnesota, New Hampshire, New York, Pennsylvania, Vermont, and Wisconsin, are now considered by CDC as "high incidence" states (those with an incidence of confirmed LD cases of $>10$ / 100,000 [47]). However, the risk within those states is not homogeneous. Multiple studies since the 1990s, in states bordering Canada, have collectively identified concentration of ticks and LD risk in the southern parts of the states that are distant from the border with Canada. This risk is changing, and ongoing northward spread of ticks and LD risk, facilitated by movements of hosts of ticks and B. burgdorferi, from the southern parts of the states has been identified in multiple studies (Michigan:
[48, 49]; Minnesota: [50]; Wisconsin: [51]; New York State: [3, 52]; Vermont: [53]; New Hampshire: [54]; Maine: [55-57]; summarised in [58]).

During the 1980s, the only known location for I. scapularis populations in Canada was at Long Point, Ontario on the north shore of Lake Erie [59]. With reports of additional I. scapularis populations on the shores of Lake Erie [60, 61], more systematic active field surveillance was initiated. Currently, southeastern and south central Canada are regions affected by the range expansion of I. scapularis and B. burgdorferi (Fig. 1). The status of LD risk in the Canadian environment, and the resulting incidence of $L D$, have been studied over the last three decades with an intensity that is possibly unique for a tick-borne disease of public health importance. Two complementary methods of tick surveillance have been employed: passive tick surveillance, and active field surveillance for ticks.

Passive tick surveillance in Canada is a FederalProvincial collaboration that involves voluntary submission of ticks found on domesticated animals and humans by participating veterinary and medical clinics and in some jurisdictions from the general public [62]. It began in 1990, has mostly national coverage, and has provided a uniquely long-term database to assess the emergence of tick populations in Canada [63]. Active field surveillance involves the collection of ticks by drag/flag sampling and capture and examination of animal hosts for ticks and is the "gold standard" method of identifying the entomological risk of LD (i.e. the presence of established tick populations and cycles of B. burgdorferi transmission) [64]. We estimate that $>2500$ individual field sites (more than double the number of meteorological stations in the whole of Canada [44]) have been visited for active field surveillance in southern Canada east of the Rockies since 2008 to follow the evolution of tick populations and infection prevalence in ticks. Many of these sites are regularly revisited, and new sites are added each year.

Active field surveillance for ticks, passive tick surveillance and human case surveillance are integrated. Information on tick abundance from passive surveillance often acts as a trigger for active field surveillance, as do clusters of human cases in locations where ticks have not been previously found. Together the results of these three types of surveillance have been regularly synthesised in peer-reviewed publications, and on provincial and federal websites, to provide the public with knowledge of where risk from LD occurs in Canada (Table 1).

The tick surveillance data provide a clear picture of the expansion of I. scapularis populations over the last two decades as an extension of the expanding LD risk in the US (Fig. 1). Expansion of the range of I. scapularis populations has been tracked year-on-year in both active 


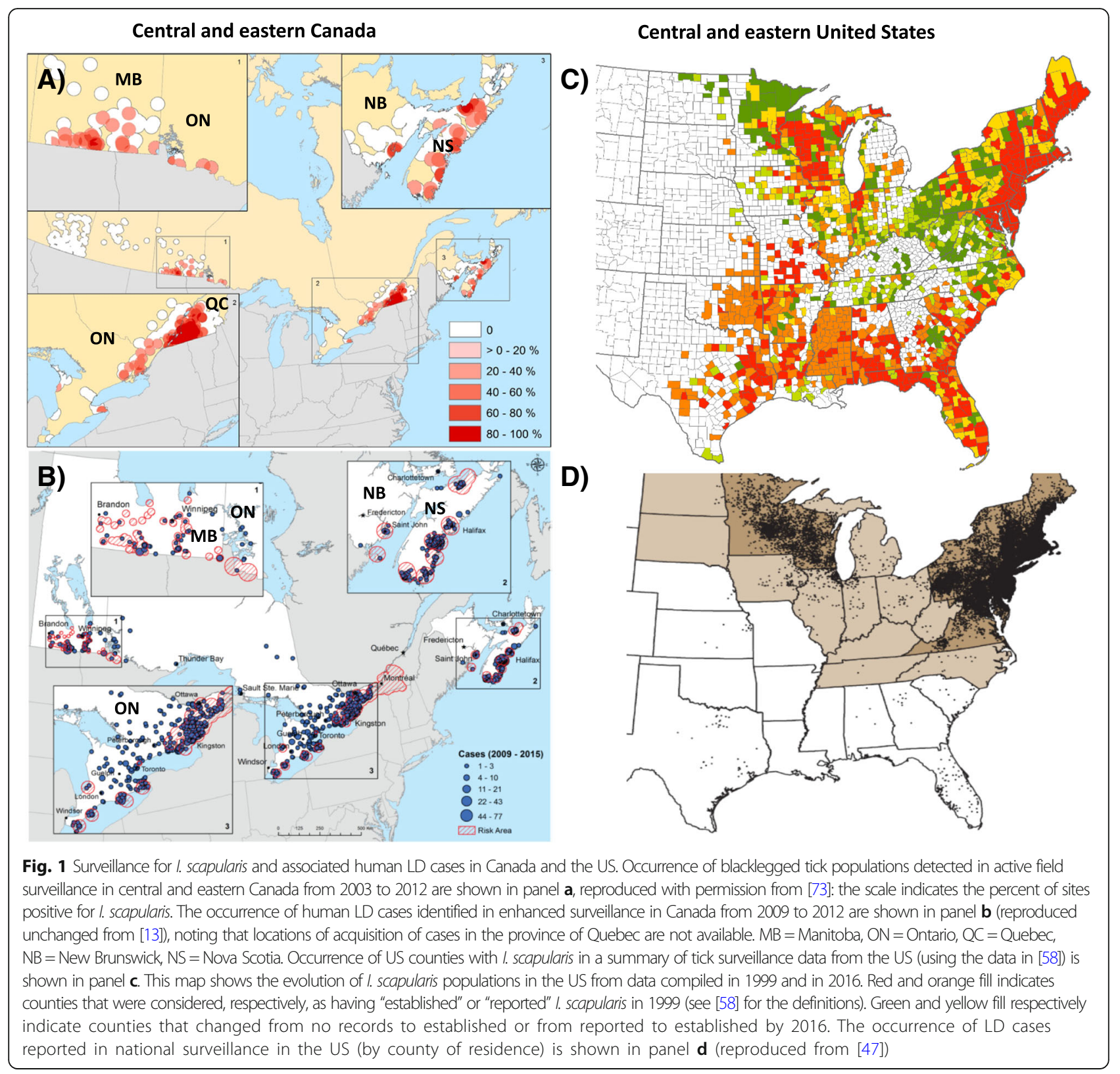

and passive surveillance data $[63,65]$. Currently, areas of Canada where I. scapularis populations have become established are increasing, but they are still somewhat limited (Fig. 1). The patterns of tick spread are geographically variable, with expansion occurring in a geographically uniform pattern in southeastern Ontario and the contiguous southern Quebec, and in southern Manitoba and the contiguous northwestern Ontario. In other areas I. scapularis populations have a more patchy occurrence, which may be due to limitations of the woodland habitats and densities of tick hosts in these regions $[64,66]$. There are also three other elements of the emergence process which continue to increase the risk of acquiring LD behind the advancing front of range expansion. These are elements of the "maturity" of the establishment of ticks and B. burgdorferi transmission cycles: i) "infilling", i.e. increasing proportions of woodland sites become occupied by ticks [65], ii) increased tick densities as the ticks continue to reproduce within the constraints of host abundance, and iii) increasing prevalence of infection in ticks $[67,68]$.

Taken as a whole, the risk of acquiring LD, and the incidence of LD, is much higher in US states bordering Canada than in Canadian provinces. However, in the border regions the distributions of tick populations and risk locations for acquiring LD are similarly heterogeneous in both countries. A prime example is Maine, where in one of two counties bordering New Brunswick 
Table 1 Examples of studies on, and syntheses of, surveillance for I. scapularis ticks, B. burgdorferi and Lyme disease cases in Canada. These include studies conducted or funded by Federal or Provincial public health organisations. These do not include articles on detection of ticks and pathogens by researchers independent of public health organisations. $A$ active field surveillance for ticks, $P$ passive tick surveillance, $H$ human case surveillance, $P$ h phylogenetic analysis, $S$ synthesis. Province abbreviations are $A B A l b e r t a, B C$ British Columbia, SK Saskatchewan, MB Manitoba, ON Ontario, QC Quebec, NB New Brunswick, NS Nova Scotia

\begin{tabular}{|c|c|c|c|}
\hline Year of surveillance/analysis & Province & Type of surveillance data & Article/website and reference number \\
\hline 1990-2003 & Canada & $P$ & Ogden et al. 2006 Ref [62] \\
\hline 1990-2008 & Canada & $A, P$ & Leighton et al. 2012 Ref [63] \\
\hline $1991-2012$ & Canada & $A, P$ & Bouchard et al. 2015 Ref [81] \\
\hline $1996-2008$ & QC & $\mathrm{A}, \mathrm{P}, \mathrm{Ph}$ & Ogden et al. 2010 Ref [67] \\
\hline $1996-2010$ & Canada & $\mathrm{A}, \mathrm{P}, \mathrm{Ph}$ & Ogden et al. 2013 Ref [68] \\
\hline 2004-2013 & Canada & $A, P$ & Ogden et al. 2014 Ref [64] \\
\hline 2005-2014 & ON & $\mathrm{H}$ & Johnson et al. 2018 Ref [43] \\
\hline 2005-2015 & $A B, S K, M B$ & A & Gabriele-Rivet et al. 2017 Ref [82] \\
\hline 2007 & QC & A & Ogden et al. 2008 Ref [83] \\
\hline $2007-2008$ & QC & A & Bouchard et al. 2011 Ref [84] \\
\hline $2007-2008$ & QC & $A, P$ & Koffi et al. 2012 Ref [85] \\
\hline $2007-2008$ & QC & $A, P$ & Bouchard et al. 2013 Ref [86] \\
\hline $2007-2012$ & QC & A & Bouchard et al. 2018 Ref [87] \\
\hline 2008-2012 & ON & $P$ & Nelder et al. 2017 Ref [88] \\
\hline $2008-2014$ & QC & $P$ & Gasmi et al. 2016 Ref [89] \\
\hline 2009-2010 & ON & A & Werden et al. 2014 Ref [90] \\
\hline 2009-2012 & Canada & $\mathrm{A}, \mathrm{H}$ & Ogden et al. 2015 Ref [40] \\
\hline 2009-2014 & QC & $A, P, H$ & Ripoche et al. 2018 Ref [91] \\
\hline 2009-2015 & Canada & $\mathrm{A}, \mathrm{H}$ & Gasmi et al. 2017 Ref [13] \\
\hline $2010-2016$ & ON & $\mathrm{P}, \mathrm{H}$ & Kulkarni et al. 2019 Ref [92] \\
\hline 2013 & QC & A & Ripoche et al. 2018 Ref [93] \\
\hline 2013-2017 & ON & $A, P$ & Schillberg et al. 2018 Ref [94] \\
\hline 2013-2014 & $\mathrm{BC}$ & A & Morshed et al. 2015 Ref [95] \\
\hline $2013-2017$ & ON & $A, P$ & Soucy et al. 2018 Ref [96] \\
\hline 2014 & NB & A & Gabriele-Rivet et al. 2015 Ref [66] \\
\hline 2014 & ON & A & Clow et al. 2016 Ref [97] \\
\hline 2014-2016 & ON & A & Clow et al. 2017 Ref [65] \\
\hline To the present & $A B$ & $A, P$ & Alberta Health Ref [98] \\
\hline To the present & $\mathrm{BC}$ & S & British Columbia Centre for Disease Control Ref [99] \\
\hline To the present & SK & $A, P, H$ & Saskatchewan Health Ref [100] \\
\hline To the present & QC & $A, P, H, S$ & INSPQ Ref [101] \\
\hline To the present & ON & A & Public Health Ontario Ref [102] \\
\hline To the present & MB & $A, P, H, S$ & Manitoba Health, Seniors and Active Living Ref [103] \\
\hline To the present & NS & $A, P, H, S$ & Nova Scotia Department of Health and Wellness Ref [104] \\
\hline To the present & NB & $A, P$ & New Brunswick Health Ref [105] \\
\hline
\end{tabular}

(Washington County) the incidence of LD in 2015 was 57.8 cases per 100,000 population. However, in Aroostook County, which lies just north of Washington County, and also borders New Brunswick, the incidence in 2015 was $2.8 / 100,000$. This is lower than the incidence in New Brunswick in the same year; there were
$1.7 / 100,000$ cases reported in New Brunswick in 2015, which could equate with 3.4/100,000 if early LD cases had been reported in New Brunswick as they were in Maine (where approximately $50 \%$ of reported cases were early LD [69]). Differences in human case incidence reported in Maine, Quebec and New Brunswick [13] are 
clearly reflected in the heterogeneity of environmental risk for LD. Extensive active field surveillance for ticks and LD risk identifies presence in southern Quebec, and southern/coastal Maine, but absence from much of New Brunswick (Fig. 2).

Limited geographic scope of areas of LD risk in Canada, as well as "immaturity" of LD risk in terms of the proportion of woodlands affected, the density of ticks and the prevalence of infection in those ticks, is consistent with low but increasing incidence of reported human cases. The wide geographic scope and maturity of LD risk in the southern parts of the neighbouring US states results in expected differences in reported state-wide and province-wide LD incidence when comparisons are made across the border (Table 2). However, there is also expected similar incidence in some locations. Reproducing populations of vector ticks are not known to be established in either Alberta or Montana, and the low and similar incidence of reported cases is because the cases are travel acquired. The tick vector I. pacificus is widely established in both British Columbia and Washington state, but it is a vector that poses a low risk of LD for humans [11] and reported LD incidence is equally low on both sides of the border (Table 2).

\section{Does prevalence of seropositivity in dogs provide evidence for under-reporting of LD in Canada?}

It has been common practice across Canada and the US for veterinarians to test dogs for seroconversion to vector-borne infections (heartworm, $L D$, ehrlichiosis and anaplasmosis) with a pet-side "SNAP" test when they present for routine check ups (the latest iteration being the IDEXX company's SNAP 4Dx Plus test: $[70,71]$ ). The LD component of the test is equivalent to the C6 Enzyme-Linked Immunosorbent Assay (ELISA), which has high specificity and sensitivity in detecting antibody responses to B. burgdorferi in dogs [72]. Consequently, routine testing across a large geographic area of North America over a number of years has produced data of interest for understanding LD risk. A number of studies in the US have found correlation between the prevalence of positive test results in dogs and the reported incidence of LD in humans from the same geographic regions over the same time periods. Analysis of similar data may be a useful adjunct to understanding LD risk

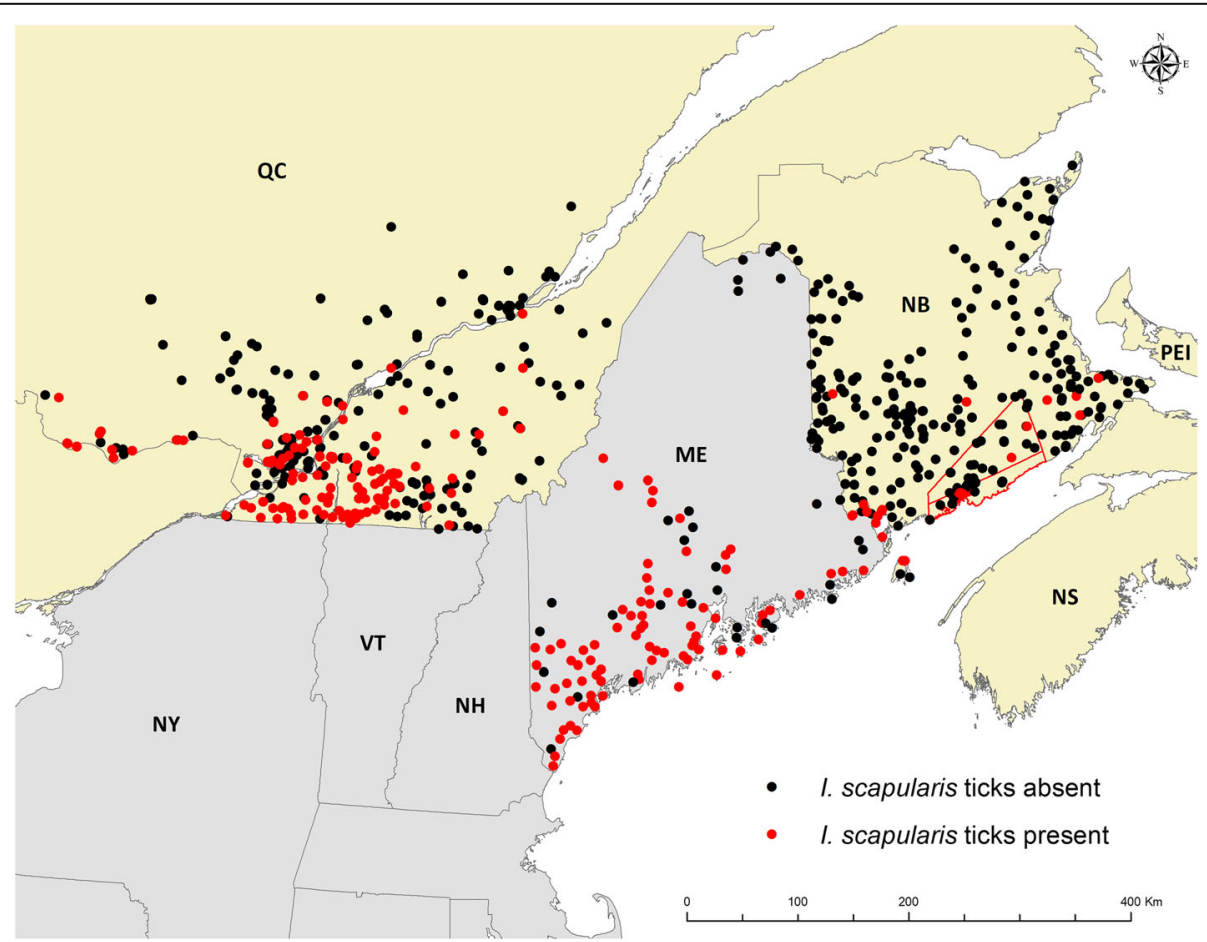

Fig. 2 Sites of active field surveillance for ticks in the contiguous region of Maine, New Brunswick and Quebec. The status of known Lyme disease risk areas in 2017 in the neighbouring regions of Quebec (data from 2007 to 2017), New Brunswick (data from 2008 to 2017) and Maine (data from 1989 to 2017) is identified using similar drag sampling methodologies in active field surveillance for ticks. Red points indicate locations where I. scapularis populations have been found and black points indicate where surveillance has occurred but the ticks were not found. Data on surveillance in Quebec are presented with the permission of Institut national de santé publique du Québec and Ministère de la Santé et des Services sociaux, and New Brunswick data are presented with the permission of New Brunswick Department of Health. The red lines indicate the adjacent counties of Kings and St. John (to the south) in New Brunswick from where the majority of human LD cases are reported, and where canine seroprevalence was particularly high in 2015 
Table 2 Comparison of reported human LD case incidence (per 100,000 population) in Canadian surveillance (probable and confirmed cases combined) in 2014 to $2016[12,13]$ with comparable data from the neighbouring US states (incidence for 2014 to 2015 obtained from [47] and for 2016 from https://www.cdc.gov/lyme/stats/tables.html, with State population estimates obtained from the US census: https://www.census.gov/data/tables/time-series/demo/popest/2010s-national-total.html\#par_textimage_ 2011805803). These data were chosen as they are contemporaneous with similar data presented in [22]. Province abbreviations are AB Alberta, BC British Columbia, MB Manitoba, ON Ontario, QC Quebec, NB New Brunswick, NS Nova Scotia. State abbreviations are MT Montana, ND North Dakota, MN Minnesota, WI Wisconsin, MI Michigan, NY New York, VT Vermont, NH New Hampshire, ME Maine, WA Washington

\begin{tabular}{|c|c|c|c|c|c|c|c|}
\hline \multirow[t]{2}{*}{ Canada } & \multicolumn{3}{|c|}{ Incidence in Canada } & \multirow{2}{*}{$\begin{array}{l}\text { Neighbouring } \\
\text { US States }\end{array}$} & \multicolumn{3}{|c|}{ Incidence in the US (fold difference) $^{a}$} \\
\hline & 2014 & 2015 & 2016 & & 2014 & 2015 & 2016 \\
\hline$\overline{A B^{b}}$ & 0.2 & 0.3 & 0.2 & MT & $0.5(2.5)$ & $0.2(0.7)$ & $1.2(6.0)$ \\
\hline $\mathrm{MB}$ & 2.7 & 2.3 & 3.9 & $\mathrm{ND}, \mathrm{MN}$ & $14.4(5.3)$ & $19.1(8.3)$ & $20.9(5.4)$ \\
\hline ON & 1.7 & 2.7 & 2.7 & MN,WI,MI,NY & $11.8(6.9)$ & $14.3(5.3)$ & $13.6(5.0)$ \\
\hline QC & 1.5 & 1.9 & 2.1 & $\mathrm{NY}, \mathrm{VT}, \mathrm{NH}, \mathrm{ME}$ & $23.3(15.5)$ & $21.7(11.4)$ & $22.8(10.9)$ \\
\hline NB & 0.7 & 1.5 & 1.5 & ME & $87.9\left(62.8^{\mathrm{C}}\right)$ & $74.7\left(24.9^{c}\right)$ & $86.4\left(28.8^{c}\right)$ \\
\hline NS & 12.1 & 26.1 & 34.4 & ME & $87.9(7.3)$ & $74.7(2.9)$ & $86.4(2.5)$ \\
\hline$B C$ & 0.1 & 0.3 & 0.8 & WA & $0.1(1.0)$ & $0.2(0.7)$ & $0.2(0.3)$ \\
\hline
\end{tabular}

${ }^{a}$ The difference between incidence in the US States compared to Canadian Provinces. Note that there are slight differences amongst Canadian provinces in the data provided in surveillance, and consequently the capacity to separate endemically acquired from travel-acquired cases. ${ }^{b}$ Only travel-related cases have been found in Alberta and neighbouring US states. 'This difference accounts for approximately $50 \%$ of reported cases in Maine being EM rash only without laboratory test results (https://www.maine.gov/dhhs/mecdc/infectious-disease/epi/vector-borne/lyme/documents/2017-Lyme-Surveillance-Report.pdf), which would not at the time have been reported in NB

in Canada, although results from previous studies, and data collected prospectively, need to be analysed carefully. Seroprevalence in dogs is a measure of the level of entomological risk (i.e. tick-borne infection) to which the dog population has been exposed over a number of years, as dogs (like humans) likely remain seropositive for multiple years following infection [57]. Furthermore, while the C6 ELISA has high specificity (96.2\%: [72]), up to $3.8 \%$ of positive test results may be false. Consequently, interpretation of low prevalence results in the tested population in Canada, which would have low pretest probability for infection (by being healthy dogs undergoing check-ups, and often being from regions where the likelihood of infection is low), need to be made with particular care. In addition, the possibility that dogs acquired infection during travel is not accounted for in the analyses as this information is not generally kept [72] although approximately $10 \%$ of positive test results may be associated with travel outside Canada [73].

Lloyd and Hawkins [22] used an estimate of 6\% seropositivity of dogs in New Brunswick to directly estimate 2569 and 6475 human LD cases in 2014 (incidences of 344 and $867 / 100,000)$ using two different methods. They also used a complicated back calculation from seropositivity in dogs, through data from passive tick surveillance, to estimate 291 human LD cases in 2014 (an incidence of 39/100,000). These estimates do not match the detailed knowledge we have of LD risk in the environment in New Brunswick at that time. Mead et al. [74] used a ballpark canine seroprevalence cut-off of $5 \%$ for states with high and low human LD case incidence. However, in most studies, seroprevalence values in dogs lower than $10 \%$ are associated with low reported human case incidence. In studies conducted in Maine in 2007 [57], values for canine seroprevalence of less than $8 \%(3.5-7.9 \%)$ were recorded in the 6 northern counties, and greater than $8 \%(8.1-34.4 \%)$ in the remaining 10 southern counties. The mean human LD incidence in those counties with seroprevalence less than $8 \%$ was $2.7 / 100,000$ (range 0-5.7), and 49.2/100,000 (range 10.3-87.2) for the southern counties where canine seroprevalence was greater than $8 \%$ (obtained using LD case data from CDC [75], and population data from the US census [76]). In "highly endemic" US states (human case incidence ranging from 10.8 to 69.1 reported cases/100,000 [47]), the prevalence of C6positive dogs has been found to range from 7.1 to $19.8 \%$ $[74,77]$. An earlier study showed that in towns in Massachusetts in which the canine seroprevalence was less than $10 \%$, the mean incidence of LD was 3.2/100,000, although this study predated the use of the C6 ELISA [78]. This study, supported by more recent findings [79], showed that the relationship between canine seroprevalence and human LD incidence is non-linear, with human LD incidence falling below 2/100,000 when canine seroprevalence was less than $6 \%$. Three Canadian studies on canine seroprevalence obtained using the IDEXX SNAP test have been published; Villeneuve et al. [73] examining IDEXX data from 2008, Herrin et al. [72] examining similar data from 2013 to 2014, and Evason et al. [80] examining the data from 2008 to 2015. In 2008, the seroprevalence in Canadian dogs was $0.72 \%$, and in 2013-2014 the combined seroprevalence was $2.5 \%$ with increases in seroprevalence in the Maritimes, 
Table 3 Seroprevalence of B. burgdorferi antibodies in dogs from Canada using the IDEXX Snap test in 2008 [73] and 2013-2014 [72], compared to human incidence of reported LD cases in Canadian provinces (mean for 2013-2014 [13]). 95\% Cl=95\% confidence intervals. Province abbreviations are BC British Columbia, AB Alberta, SK Saskatchewan, MB Manitoba, ON Ontario, QC Quebec, NB New Brunswick, NS Nova Scotia, PEI Prince Edward Island

\begin{tabular}{llll}
\hline Province & $\begin{array}{l}2008 \text { canine seroprevalence } \\
\text { data }(\% \text { and } 95 \mathrm{Cl})\end{array}$ & $\begin{array}{l}\text { 2013-2014 canine seroprevalence } \\
\text { data }(\% \text { and } 95 \mathrm{Cl}) \text { [65] }\end{array}$ & $\begin{array}{l}\text { Mean incidence (2013-2014) of human } \\
\text { Lyme disease in Canadian provinces }\end{array}$ \\
\hline BC & $0(0-0.09)$ & & 0.10 \\
AB & $0.17(<0.01-0.64)$ & $0.54(0.01-3.30)$ & 0.35 \\
SK & $0.34(<0.01-1.24)$ & $2.4(2.1-2.7)$ & 0.05 \\
MB & $1.90(1.70-2.15)$ & $2.3(2.2-2.4)$ & 2.5 \\
ON & $0.47(0.42-0.53)$ & $2.8(2.6-3.0)$ & 2.0 \\
QC & $0.57(0.45-0.71)$ & $3.7(2.9-4.7)$ & 1.6 \\
NB & $0.66(0.01-3.63)$ & $15.7(11.4-21.3)$ & 0.7 \\
NS & $2.15(1.21-3.52)$ & & 14.1 \\
PEI & $10.0(2.11-26.52)$ & & 0 \\
Total for Canada & $0.72(0.67-0.78)$ & $2.46(2.37-2.55)$ & 1.7
\end{tabular}

Quebec, Ontario and Manitoba from 2008 to 2013-2014 (Table 3). The low but increasing seroprevalence in dogs is consistent with our knowledge of the level of entomological risk of LD in Canada obtained by tick surveillance. One outlier datum presented in Evason et al. [80] is a seroprevalence value of $8.8 \%$ (53/604) in dogs from New Brunswick in 2015, which is more than double the seroprevalence in dogs from this province in 2013 to 2014 combined (Table 3). Closer inspection of the data provided to us by the authors show, however, that many of the positive test results came from veterinary practices in the neighbouring New Brunswick counties of St John and Kings, which are identified by active field surveillance for ticks as LD risk areas (Fig. 2). The prevalence in these samples is clearly much higher $(35 / 207,16.9 \%)$, than in those from the rest of the province where seroprevalence remains at a level comparable to that in 2013-2014 (18/ $397,4.5 \%)$. This is consistent with the majority of human LD cases (13 of 20 for the whole province) being reported as having been acquired in these counties from 2013 to 2015 , with a maximum incidence in 2015 of 5.6/100,000, versus 2.0/100,000 for the rest of the province (personal communication, J Badcock). Human LD incidence continues to rise in this region of New Brunswick and by 2017 the incidence in these counties (combined) had risen to $14.7 / 100,000$ (personal communication, J Badcock). Consistent with [74], these data suggest that canine seroprevalence values may be able to identify emerging hotspots of LD risk. However, they also indicate that careful analysis of the spatial pattern of the data is required to interpret seroprevalence values across broad geographic areas, particularly when the number of samples is relatively small. Overall, the reported LD incidence in humans in Canada is consistent with the observed low prevalence of positive canine sera, which does not provide any evidence for the presence of significant under-reporting of human LD cases.

\section{Conclusion}

Our comparisons of human case LD incidence, as reported in surveillance and as suggested by canine seroprevalence, in the US and Canada do not support the idea that there is a high degree of under-reporting ( $<10 \%$ of cases reported) in Canadian human case surveillance. Even if it could be argued that these comparisons are themselves plagued by underreporting, the extensive surveillance efforts conducted in Canada mean that we have a strong understanding of where LD risk is occurring, how it has evolved and in what ways it is similar to, and different from, that occurring in neighbouring US states. It is clear that, as for other reportable disease surveillance programs, under-reporting of LD occurs in Canada, and in part the surveillance is designed to discover this. However, tick surveillance data, combined with evidence from serological studies in dogs, do not suggest high levels of under-reporting in Canada. We speculate that the rate of under-reporting in Canada may be similar to that seen in regions where LD is emerging in the US [20]. The precise degree of under-reporting is unknown, and further prospective studies are needed to measure this.

\footnotetext{
Abbreviations

CDC: United States Centres for Disease Control \& Prevention; ElA: Enzyme immune assay; ELISA: Enzyme linked immunosorbent assay; EM: Erythema migrans; INSPQ: Institut national de santé publique du Québec; LD: Lyme disease; PHAC: Public Health Agency of Canada
}

\section{Acknowledgements}

We thank Yann Pelcat for providing the maps in Figs. 1 and 2. We thank Institut national de santé publique du Québec, Ministère de la Santé et des Services sociaux of Quebec and New Brunswick Department of Health for permission to use field tick surveillance data. We thank Dr. Michelle Evason, Atlantic Veterinary College, and Dr. J. Scott Weese, Ontario Veterinary College for providing canine seroprevalence data for New Brunswick in 2015. 


\section{Authors' contributions}

$\mathrm{NHO}, \mathrm{TH}, \mathrm{JB}, \mathrm{LRL}, \mathrm{MAD}$ and DW conceived the study; JKK manages human case surveillance in Canada and provided and advised on relevant data; PAL and CB obtained and managed Quebec active field surveillance data; RPS, CBL and SPE together collected, provided and advised on surveillance data from Maine; ASP provided key advice on interpretation of serological data from, and studies on, dogs; and all contributed to writing. All authors have read and approved the manuscript.

\section{Funding}

Authors are funded by their host organisations. NHO, LRL, MAD, JKK and CB by the Public Health Agency of Canada; TH by Nova Scotia Health Authority and Dalhousie University; JB by New Brunswick Department of Health; DW by Dalhousie University and Saint John Regional Hospital; PAL by Université de Montréal; ASP by University of Guelph; and RPS, CBL and SPE by Maine Medical Center Research Institute. Funding for data collection came from the author's host organisations, with the exception of data obtained from other sources as identified in the "Availability of data and materials" section.

\section{Availability of data and materials}

Tick surveillance data that support the findings of this study are available from Anne Kimpton and Dr. Jacqueline Badcock (of Institut national de santé publique du Québec and New Brunswick Department of Health respectively), and Dr. Robert Smith (Maine Medical Center Research Institute) but restrictions apply to the availability of these data, which were used under license for the current study, and so are not publicly available. These data are however available from the authors upon reasonable request and with permission of Institut national de santé publique du Québec, Ministère de la Santé et des Services sociaux, New Brunswick Department of Health and Maine Medical Center Research Institute. Data on distributions of I. scapularis in the US in Fig. 1 panel $C$ are available from Dr. Rebecca Eisen, US CDC. Canine seroprevalence data for New Brunswick in 2015 are available from IDEXX Laboratories, Inc. (IDEXX Drive, Westbrook, Maine 04092, US), but restrictions apply to the availability of these data, which were used under license for the current study, and so are not publicly available. These data are however available from IDEXX Laboratories, Inc. upon reasonable request and with permission.

\section{Ethics approval and consent to participate}

Not applicable. All human case data in this article are anonymized data freely available from the sources identified.

\section{Consent for publication}

Not applicable. This article does not contain information from any individual person that would require consent.

\section{Competing interests}

The authors declare that they have no competing interests.

\section{Author details}

${ }^{1}$ Public Health Risk Sciences Division, National Microbiology Laboratory, Public Health Agency of Canada, St. Hyacinthe, Canada. ${ }^{2}$ Office of the Chief Medical Officer of Health, New Brunswick Department of Health, Fredericton, Canada. ${ }^{3}$ Zoonotic Diseases and Special Pathogens Division, National Microbiology Laboratory, Public Health Agency of Canada, Winnipeg, Canada. ${ }^{4}$ Maine Medical Center Research Institute, Scarborough, ME, USA. ${ }^{5}$ Department of Pathology and Laboratory Medicine, Nova Scotia Health Authority and Dalhousie University, Halifax, NS, Canada. ${ }^{6}$ Policy Integration and Zoonoses Division, Centre for Food-Borne, Environmental and Zoonotic Diseases, Public Health Agency of Canada, Ottawa, Canada. ${ }^{7}$ Département de pathologie et microbiologie, and Groupe de recherche en épidémiologie des zoonoses et santé publique (GREZOSP), Faculté de médecine vétérinaire, Université de Montréal, Québec, Canada. ${ }^{8}$ Department of Pathobiology, Ontario Veterinary College, University of Guelph, Guelph, Canada. ${ }^{9}$ Department of Medicine, Division of Infectious Diseases, Faculty of Medicine, Saint John Regional Hospital, Dalhousie University, Saint John, New Brunswick, Canada.
Received: 22 March 2019 Accepted: 20 June 2019

Published online: 28 June 2019

\section{References}

1. Ogden NH, Lindsay RL, Sockett PN, Morshed M, Artsob H. Emergence of Lyme disease in Canada. CMAJ. 2009;180:1221-4.

2. Kilpatrick AM, Dobson ADM, Levi T, Salkeld DJ, Swei A, Ginsberg S, et al. Lyme disease ecology in a changing world: consensus, uncertainty, and critical gaps for improving control. Philos Trans R Soc Lond Ser B Biol Sci. 2017;372:20160117.

3. Khatchikian CE, Prusinski M, Stone M, Backenson PB, Wang IN, Levy MZ, et al. Geographical and environmental factors driving the increase in the Lyme disease vector Ixodes scapularis. Ecosphere. 2012;3:art85.

4. Smith RP Jr, Rand PW, Lacombe EH, Morris SR, Holmes DW, Caporale DA. Role of bird migration in the long-distance dispersal of Ixodes dammini, the vector of Lyme disease. J Infect Dis. 1996;174:221-4.

5. Rand PW, Lacombe EH, Smith RP Jr, Ficker J. Participation of birds (Aves) in the emergence of Lyme disease in southern Maine. J Med Entomol. 1998; 35:270-6.

6. Ogden NH, Lindsay RL, Hanincová K, Barker IK, Bigras-Poulin M, Charron DF, et al. The role of migratory birds in introduction and range expansion of Ixodes scapularis ticks, and Borrelia burgdorferi and Anaplasma phagocytophilum in Canada. Appl Environ Microbiol. 2008;74:1780-90.

7. Elias SP, Smith RP Jr, Morris SR, Rand PW, Lubelczyk C, Lacombe EH. Density of Ixodes scapularis ticks on Monhegan Island after complete deer removal: a question of avian importation? J Vector Ecol. 2011;36:11-23.

8. Ebi KL, Ogden NH, Semenza JC, Woodward A. Detecting and attributing health burdens to climate change. Environ Health Perspect. 2017;125: 085004.

9. Simon JA, Marrotte RR, Desrosiers N, Fiset J, Gaitan J, Gonzalez A, et al. Climate change, habitat fragmentation, ticks and the white-footed mouse drive occurrence of Borrelia burgdorferi, the agent of Lyme disease, at the northern limit of its distribution. Evol Appl. 2014;7:750-64.

10. Arthur DR, Snow KR. Ixodes pacificus Cooley and Kohls, 1943: its life-history and occurrence. Parasitology. 1968;58:893-906.

11. Eisen $\mathrm{R}$, Eisen $\mathrm{L}$, Ogden NH, Beard CB. Linkages of weather and climate with Ixodes scapularis and Ixodes pacificus (Acari: Ixodidae), enzootic transmission of Borrelia burgdorferi, and Lyme disease in North America. J Med Entomol. 2015;53:250-61.

12. Government of Canada, Surveillance of Lyme disease. https://www.canada. $\mathrm{ca} /$ en/public-health/services/diseases/lyme-disease/surveillance-lymedisease.html. Accessed 24 June 2019.

13. Gasmi S, Ogden NH, Lindsay LR, Phillips J, Burns S, Fleming S, et al. Surveillance for Lyme disease in Canada: 2009-2015. Can Commun Dis Rep. 2017:43:194-9.

14. Ogden NH. Vector-borne disease, climate change and urban design. Can Commun Dis Rep. 2016;42:202-3.

15. Aenishaenslin C, Bouchard C, Koffi JK, Pelcat Y, Ogden NH. Evidence of rapid changes in Lyme disease awareness in Canada. Ticks Tick Borne Dis. 2016;7: 1067-74.

16. Centers for Disease Control and Prevention. Principles of epidemiology in public health practice. In: An introduction to applied epidemiology and biostatistics. Third ed. file:///C:/Users/nogden/Downloads/cdc_6914_DS1.pdf. Accessed 21 May 2019.

17. Gibbons $\mathrm{CL}$, Mangen MJ, Plass D, Havelaar AH, Brooke RJ, Kramarz P, et al. Measuring underreporting and under-ascertainment in infectious disease datasets: a comparison of methods. BMC Public Health. 2014;14:147.

18. Majowicz SE, Edge VL, Fazil A, McNab WB, Doré KA, Sockett PN, et al. Estimating the under-reporting rate for infectious gastrointestinal illness in Ontario. Can J Public Health. 2005:96:178-81.

19. MacDougall L, Majowicz S, Doré K, Flint J, Thomas K, Kovacs S, et al. Underreporting of infectious gastrointestinal illness in British Columbia, Canada: who is counted in provincial communicable disease statistics? Epidemiol Infect. 2008; 136:248-56.

20. Naleway AL, Belongia EA, Kazmierczak JJ, Greenlee RT, Davis JP. Lyme disease incidence in Wisconsin: a comparison of state-reported rates and rates from a population-based cohort. Am J Epidemiol. 2002;155:1120-7.

21. Nelson CA, Saha S, Kugeler KJ, Delorey MJ, Shankar MB, Hinckley AF, et al. Incidence of clinician-diagnosed Lyme disease, United States, 2005-2010. Emerg Infect Dis. 2015;21:1625-31. 
22. Lloyd VK, Hawkins RG. Under-detection of Lyme disease in Canada. Healthcare (Basel). 2018;6:E125.

23. Cook MJ, Puri BK. Commercial test kits for detection of Lyme borreliosis: a meta-analysis of test accuracy. Int J Gen Med. 2016;9:427-40.

24. Fallon BA, Pavlicova M, Coffino SW, Brenner C. A comparison of Lyme disease serologic test results from 4 laboratories in patients with persistent symptoms after antibiotic treatment. Clin Infect Dis. 2014;59:1705-10.

25. Waddell L, Greig J, Mascarenhas M, Harding S, Lindsay LR, Ogden NH. The accuracy of diagnostic tests for Lyme disease in humans, a systematic review and meta-analysis of North American research. Plos One. 2016;11:e0168613.

26. Wormser GP, Dattwyler RJ, Shapiro ED, Halperin JJ, Steere AC, Klempner MS et al. The clinical assessment, treatment, and prevention of Lyme disease, human granulocytic anaplasmosis, and babesiosis: clinical practice guidelines by the Infectious Diseases Society of America. Clin Infect Dis. 2006;43:1089-134.

27. National Institute for Health and Care Excellence, UK, Lyme disease guideline. https://www.nice.org.uk/guidance/ng95. Accessed 24 June 2019

28. Ogden NH, Feil EJ, Leighton PA, Lindsay LR, Margos G, Mechai S, et al. Evolutionary aspects of emerging Lyme disease in Canada. Appl Environ Microbiol. 2015;81:7350-9.

29. Mechai S, Margos G, Feil EJ, Lindsay LR. Ogden NH Phylogeographic analysis reveals a complex population structure of Borrelia burgdorferi in southern Canada. Appl Environ Microbiol. 2015;81:1309-18.

30. Walter KS, Carpi G, Caccone A, Diuk-Wasser MA. Genomic insights into the ancient spread of Lyme disease across North America. Nat Ecol Evol. 2017;1: 1569-76.

31. Molins CR, Delorey MJ, Sexton C, Schriefer ME. Lyme borreliosis serology: performance of several commonly used laboratory diagnostic tests and a large resource panel of well-characterized patient samples. J Clin Microbiol. 2016:54:2726-34.

32. Patriquin G, LeBlanc J, Heinstein C, Roberts C, Lindsay R, Hatchette TF. Cross-reactivity between Lyme and syphilis screening assays: Lyme disease does not cause false-positive syphilis screens. Diagn Microbiol Infect Dis. 2016;84:184-6

33. Pegalajar-Jurado A, Schriefer ME, Welch RJ, Couturier MR, MacKenzie T, Clark $\mathrm{RJ}$, et al. Evaluation of modified two-tiered testing algorithms for Lyme disease laboratory diagnosis using well-characterized serum samples. J Clin Microbiol. 2018;56:e01943-17.

34. Tugwell P, Dennis DT, Weinstein A, Wells G, Shea B, Nichol G, et al. Laboratory evaluation in the diagnosis of Lyme disease. Ann Intern Med. 1997;127:1109-23.

35. Lantos PM, Branda JA, Boggan JC, Chudgar SM, Wilson EA, Ruffin F, et al. Poor positive predictive value of Lyme disease serologic testing in an area of low disease incidence. Clin Infect Dis. 2015;61:1374-80.

36. Hatchette TF, Johnston BL, Schleihauf E, Mask A, Haldane D, Drebot M, et al. Epidemiology of Lyme disease, Nova Scotia, Canada, 2002-2013. Emerg Infect Dis. 2015;21:1751-8.

37. Gomes-Solecki MJ, Wormser GP, Persing DH, Berger BW, Glass JD, Yang X, et al. A first-tier rapid assay for the serodiagnosis of Borrelia burgdorferi infection. Arch Intern Med. 2001;161:2015-20.

38. Gomes-Solecki MJ, Wormser GP, Schriefer M, Neuman G, Hannafey L, Glass $J D$, et al. Recombinant assay for serodiagnosis of Lyme disease regardless of OspA vaccination status. J Clin Microbiol. 2002;40:193-7.

39. Public Health Agency of Canada (PHAC). Case definitions for communicable diseases under national surveillance. Can Commun Dis Rep. 2009;35:S2.

40. Ogden NH, Koffi JK, Lindsay LR, Fleming S, Mombourquette DC, Sanford C, et al. Surveillance for Lyme disease in Canada, 2009-2012. Can Commun Dis Rep. 2015;41:132-45.

41. Henry B, Crabtree A, Roth D, Blackman D, Morshed M. Lyme disease: knowledge, beliefs, and practices of physicians in a low-endemic area. Can Fam Physician. 2012;58:e289-95.

42. Gasmi S, Ogden NH, Leighton PA, Adam-Poupart A, Milord F, Lindsay LR, et al. Practices of Lyme disease diagnosis and treatment by general practitioners in Quebec, 2008-2015. BMC Fam Pract. 2017;18:65.

43. Johnson KO, Nelder MP, Russell C, Li Y, Badiani T, Sander B, et al. Clinical manifestations of reported Lyme disease cases in Ontario, Canada: 20052014. PLoS One. 2018;13:e0198509.

44. Government of Canada, Lyme Disease in Canada - A Federal Framework. https://www.canada.ca/en/public-health/services/publications/diseasesconditions/lyme-disease-canada-federal-framework.html\#a5-2. Accessed 24 June 2019.
45. Steere AC, Malawista SE, Snydman DR, Shope RE, Andiman WA, Ross MR, et al. Lyme arthritis: an epidemic of oligoarticular arthritis in children and adults in three Connecticut communities. Arthritis Rheum. 1977;20:7-17.

46. Diuk-Wasser MA, Gatewood AG, Cortinas MR, Yaremych-Hamer S, Tsao J, Kitron $U$, et al. Spatiotemporal patterns of host-seeking Ixodes scapularis nymphs (Acari : lodidae) in the United States. J Med Entomol. 2006;43:166-76.

47. Schwartz AM, Hinckley AF, Mead PS, Hook SA, Kugeler KJ. Surveillance for Lyme disease - United States, 2008-2015. MMWR Surveill Summ. 2017;66:1-12.

48. Hamer SA, Tsao Jl, Walker ED, Hickling GJ. Invasion of the Lyme disease vector Ixodes scapularis: implications for Borrelia burgdorferi endemicity. Ecohealth. 2010;7:47-63.

49. Lantos PM, Tsao J, Nigrovic LE, Auwaerter PG, Fowler VG, Ruffin F, et al. Geographic expansion of Lyme disease in Michigan, 2000-2014. Open Forum Infect Dis. 2017;4:269.

50. Robinson SJ, Neitzel DF, Moen RA, Craft ME, Hamilton KE, Johnson LB, et al. Disease risk in a dynamic environment: the spread of tick-borne pathogens in Minnesota, USA. Ecohealth. 2015;12:152-63.

51. Guerra M, Walker E, Jones C, Paskewitz S, Cortinas MR, Stancil A, et al. Predicting the risk of Lyme disease: habitat suitability for Ixodes scapularis in the north Central United States. Emerg Infect Dis. 2002;8:289-97.

52. Oliver J, Means RG, Kogut S, Prusinski M, Howard JJ, Layne LJ, et al. Prevalence of Borrelia burgdorferi in small mammals in New York state. J Med Entomol. 2006;43:924-35.

53. Serra AC, Warden PS, Fricker CR, Giese AR. Distribution of ticks and prevalence of Borrelia burgdorferi in the upper Connecticut river valley of Vermont. Northeast Nat (Steuben). 2013;20:197-204.

54. Walk ST, Xu G, Stull JW, Rich SM. Correlation between tick density and pathogen endemicity, New Hampshire. Emerg Infect Dis. 2009;15:585-7.

55. Rand PW, Smith RP Jr, Lacombe EH. Canine seroprevalence and the distribution of Ixodes dammini in an area of emerging Lyme disease. Am J Public Health. 1991;81:1331-4.

56. Rand PW, Lacombe EH, Dearborn R, Cahill B, Elias S, Lubelczyk CB, et al. Passive surveillance in Maine, an area emergent for tick-borne diseases. J Med Entomol. 2007:44:1118-29.

57. Rand PW, Lacombe EH, Elias SP, Cahill BK, Lubelczyk CB, Smith RP Jr. Multitarget test for emerging Lyme disease and anaplasmosis in a serosurvey of dogs, Maine, USA. Emerg Infect Dis. 2011;17:899-902.

58. Eisen RJ, Eisen L, Beard CB. County-scale distribution of Ixodes scapularis and Ixodes pacificus (Acari: Ixodidae) in the continental United States. J Med Entomol. 2016;53:349-86.

59. Barker IK, Surgeoner GA, Artsob H, McEwen SA, Elliott LA, Campbell GD, et al. Distribution of the Lyme disease vector, Ixodes dammini (Acari: Ixodidae) and isolation of Borrelia burgdorferi in Ontario, Canada. J Med Entomol. 1992;29:1011-22.

60. Morshed MG, Scott JD, Fernando K, Mann RB, Durden LA. Lyme disease spirochete, Borrelia burgdorferi endemic at epicenter in rondeau Provincial Park, Ontario. J Med Entomol. 2003:40:91-4.

61. Scott JD, Lee MK, Fernando K, Jorgensen DR, Durden LA, Morshed MG. Rapid introduction of Lyme disease spirochete, Borrelia burgdorferi sensu stricto, in Ixodes scapularis (Acari: Ixodidae) established at Turkey point Provincial Park, Ontario, Canada. J Vector Ecol. 2008;33:64-9.

62. Ogden NH, Trudel L, Artsob H, Barker IK, Beauchamp G, Charron D, et al. Ixodes scapularis ticks collected by passive surveillance in Canada: analysis of geographic distribution and infection with the Lyme borreliosis agent Borrelia burgdorferi. J Med Entomol. 2006:43:600-9.

63. Leighton P, Koffi J, Pelcat Y, Lindsay LR, Ogden NH. Predicting the speed of tick invasion: an empirical model of range expansion for the Lyme disease vector Ixodes scapularis in Canada. J Appl Ecol. 2012:49:457-64.

64. Ogden NH, Koffi JK, Pelcat Y. Lindsay LR environmental risk from Lyme disease in central and eastern Canada: a summary of recent surveillance information. Can Commun Dis Rep. 2014:40:74-82

65. Clow K, Leighton PA, Ogden NH, Lindsay LR, Michel P, Pearl D, et al. Northward range expansion of Ixodes scapularis evident over a short timescale in Ontario, Canada. Plos One. 2017;12:e0189393.

66. Gabriele-Rivet V, Arsenault J, Badcock J, Cheng A, Edsall J, Goltz J, et al. Different ecological niches for ticks of public health significance in Canada. PLoS One. 2015;10:e0131282.

67. Ogden NH, Bouchard C, Kurtenbach K, Margos G, Lindsay LR, Trudel L, et al. Active and passive surveillance, and phylogenetic analysis of Borrelia burgdorferi elucidate the process of Lyme disease risk emergence in Canada. Environ Health Perspect. 2010;118:909-14. 
68. Ogden $N H$, Lindsay $L R$, Leighton P. Predicting the rate of invasion of the agent of Lyme disease, Borrelia burgdorferi in North America. J Appl Ecol. 2013;50:510-8

69. Maine Center for Disease Control and Prevention, Lyme disease Maine surveillance report 2017. https://www.maine.gov/dhhs/mecdc/infectiousdisease/epi/vector-borne/lyme/documents/2017-Lyme-Surveillance-Report pdf. Accessed 24 June 2019.

70. IDEXX SNAP 4Dx Plus Test. https://ca.idexx.com/en-ca/veterinary/snap-tests/ snap-4dx-plus-test/. Accessed 24 June 2019.

71. Peregrine AS, Barker IK, Abrams-Ogg AC, Woods JP. Screening dogs in Ontario for Borrelia burgdorferi and Ehrlichia canis should be selective rather than routine. Can Vet J. 2007:48:673.

72. Herrin BH, Peregrine AS, Goring J, Beall MJ, Little SE. Canine infection with Borrelia burgdorferi, Dirofilaria immitis, Anaplasma spp. and Ehrlichia spp. in Canada, 2013-2014. Parasit Vectors. 2017;10:244.

73. Villeneuve A, Goring J, Marcotte L, Overvelde S. Seroprevalence of Borrelia burgdorferi, Anaplasma phagocytophilum, Ehrlichia canis, and Dirofilaria immitis among dogs in Canada. Can Vet J. 2011;52:527-30.

74. Mead P, Goel R, Kugeler K. Canine serology as adjunct to human Lyme disease surveillance. Emerg Infect Dis. 2011;17:1710-2.

75. Centers for Disease Control and Prevention. Lyme disease data tables. https://www.cdc.gov/lyme/stats/tables.html. Accessed 24 June 2019.

76. US Census Bureau Fact Finder. https://factfinder.census.gov/faces/nav/jsf/ pages/searchresults.xhtml?refresh=t. Accessed 24 June 2019.

77. Bowman D, Little SE, Lorentzen L, Shields J, Sullivan MP, Carlin EP Prevalence and geographic distribution of Dirofilaria immitis, Borrelia burgdorferi, Ehrlichia canis, and Anaplasma phagocytophilum in dogs in the United States: results of a national clinic-based serologic survey. Vet Parasitol. 2009;160:138-48.

78. Lindenmayer JM, Marshall D, Onderdonk AB. Dogs as sentinels for Lyme disease in Massachusetts. Am J Public Health. 1991;81:1448-55.

79. Liu Y, Nordone SK, Yabsley MJ, Lund RB, McMahan CS, Gettings JR. Quantifying the relationship between human Lyme disease and Borrelia burgdorferi exposure in domestic dogs. Geospat Health. 2019;14:1.

80. Evason M, Stull JW, Pearl DL, Peregrine AS, Jardine C, Buch JS, et al. Prevalence of Borrelia burgdorferi, Anaplasma spp., Ehrlichia spp. and Dirofilaria immitis in Canadian dogs, 2008 to 2015: a repeat cross-sectional study. Parasit Vectors. 2019;12:64.

81. Bouchard C, Leonard E, Koffi JK, Pelcat Y, Peregrine A, Chilton N, et al. The increasing risk of Lyme disease in Canada. Can Vet J. 2015;56:693-9.

82. Gabriele-Rivet V, Koffi JK, Pelcat Y, Arsenault J, Cheng A, Lindsay LR, et al. A risk model for the Lyme disease vector Ixodes scapularis (Acari: Ixodidae) in the prairie provinces of Canada. J Med Entomol. 2017:54:862-8.

83. Ogden NH, St-Onge L, Barker IK, Brazeau S, Bigras-Poulin M, Charron DF, et al. Risk maps for range expansion of the Lyme disease vector, Ixodes scapularis, in Canada now and with climate change. Int J Health Geogr. 2008;7:24.

84. Bouchard C, Beauchamp G, Nguon S, Trudel L, Milord F, Lindsay LR, et al. Associations between Ixodes scapularis ticks and small mammal hosts in a newly-endemic zone in southeastern Canada: implications for Borrelia burgdorferi transmission. Ticks Tick Borne Dis. 2011;2:183-90.

85. Koffi JK, Leighton PA, Pelcat Y, Trudel L, Lindsay LR, Ogden NH. Passive surveillance for Ixodes scapularis ticks: enhanced analysis for early detection of emerging Lyme disease risk. J Med Entomol. 2012;49:400-9.

86. Bouchard C, Leighton P, Beauchamp G, Nguon S, Trudel L, Milord F, et al. Harvested white-tailed deer as sentinel hosts for early establishing Ixodes scapularis populations and risk from vector-borne zoonoses in southeastern Canada. J Med Entomol. 2013;50:384-93.

87. Bouchard C, Aenishaenslin C, Rees EE, Koffi JK, Pelcat Y, Ripoche M, et al Integrated social-behavioral and ecological risk maps to prioritize local public health responses to Lyme disease. Environ Health Perspect. 2018;126: 047008.

88. Nelder MP, Russell C, Lindsay LR, Dhar B, Patel SN, Johnson S, et al. Population-based passive tick surveillance and detection of expanding foci of blacklegged ticks Ixodes scapularis and the Lyme disease agent Borrelia burgdorferi in Ontario, Canada. PLoS One. 2014;9:e105358.

89. Gasmi S, Ogden NH, Leighton PA, Lindsay RL. Thivierge K analysis of the human population bitten by Ixodes scapularis ticks in Quebec, Canada: increasing risk of Lyme disease. Ticks Tick-borne Dis. 2016;7:1075-81.

90. Werden L, Barker IK, Bowman J, Gonzales EK, Leighton PA, Lindsay LR, et al. Geography, deer, and host biodiversity shape the pattern of Lyme disease emergence in the Thousand Islands archipelago of Ontario, Canada. PLoS One. 2014;9:e85640.

91. Ripoche M, Gasmi S, Adam-Poupart A, Koffi JK, Lindsay LR, Ludwig A, et al. Passive tick surveillance provides an accurate early signal of emerging Lyme disease risk and human cases in southern Canada. J Med Entomol. 2018;55: 1016-26.

92. Kulkarni MA, Narula I, Slatculescu AM, Russell C. Lyme disease emergence after invasion of the blacklegged tick, Ixodes scapularis, Ontario, Canada, 2010-2016. Emerg Infect Dis. 2019;25:328-32.

93. Ripoche $M$, Lindsay LR, Ludwig A, Ogden NH, Thivierge $H$, Leighton PA. Multi-scale clustering of Lyme disease risk at the expanding leading edge of the range of Ixodes scapularis in Canada. Int J Environ Res Public Health. 2018;15:E603.

94. Schillberg E, Lunny D, Lindsay LR, Nelder MP, Russell C, Mackie M, et al. Distribution of Ixodes scapularis in northwestern Ontario: results from active and passive surveillance activities in the northwestern health unit catchment area. Int J Environ Res Public Health. 2018;15:E2225.

95. Morshed MG, Lee MK, Man S, Fernando K, Wong Q, Hojgaard A, et al. Surveillance for Borrelia burgdorferi in Ixodes ticks and small rodents in British Columbia. Vector Borne Zoonotic Dis. 2015;15:701-5.

96. Soucy J-PR, Slatculescu AM, Nyiraneza C, Ogden NH, Leighton PA, Kerr JT, et al. High-resolution ecological niche modelling of Ixodes scapularis ticks based on passive surveillance data at the northern frontier of Lyme disease emergence in North America. Vector Borne Zoonotic Dis. 2018;18:235-42.

97. Clow K, Ogden NH, Lindsay LR, Michel P, Pearl D, Jardine C. Distribution of ticks and the risk of Lyme disease and other tick-borne pathogens of public health significance in Ontario, Canada. Vector Borne Zoonotic Dis. 2016;16: 215-22.

98. Alberta Health, Lyme disease and tick surveillance. https://www.alberta.ca/ lyme-disease-tick-surveillance.aspx. Accessed 24 June 2019.

99. British Columbia Centre for Disease Control, Lyme disease risk areas. http:// www.bccdc.ca/resource-gallery/Documents/Statistics\%20and\%20Research/ Statistics\%20and\%20Reports/Epid/Vector-bourne/Lyme_Disease_Risk_Areas_ Map_BC_June_2013.pdf. Accessed 24 June 2019.

100. Saskatchewan Health, Lyme disease. https://www.saskatchewan.ca/ residents/health/diseases-and-conditions/lyme-disease\#surveillance-data. Accessed 24 June 2019.

101. INSPQ, Lyme disease and diseases transmitted by ticks. https://www.inspq. qc.ca/zoonoses/maladie-de-lyme. Accessed 24 June 2019

102. Public Health Ontario, Ontario Lyme disease map 2019. https://www. publichealthontario.ca/-/media/documents/lyme-disease-risk-area-map-2019.

103. Manitoba Health, Seniors and active living. Annual tick-borne disease report https://www.gov.mb.ca/health/publichealth/cdc/tickborne/docs/tbd_ report2016.pdf. Accessed 24 June 2019.

104. Nova Scotia Department of Health and Wellness, Lyme disease. https:// novascotia.ca/dhw/CDPC/lyme.asp. Accessed 24 June 2019.

105. New Brunswick Office of the Chief Medical Officer of Health. https://www2. gnb.ca/content/gnb/en/departments/ocmoh/cdc/content/vectorborne_ andzoonotic/Tick-Borne_Diseases/risk.html. Accessed 24 June 2019.

\section{Publisher's Note}

Springer Nature remains neutral with regard to jurisdictional claims in published maps and institutional affiliations.

Ready to submit your research? Choose BMC and benefit from:

- fast, convenient online submission

- thorough peer review by experienced researchers in your field

- rapid publication on acceptance

- support for research data, including large and complex data types

- gold Open Access which fosters wider collaboration and increased citations

- maximum visibility for your research: over $100 \mathrm{M}$ website views per year

At $\mathrm{BMC}$, research is always in progress.

Learn more biomedcentral.com/submissions 